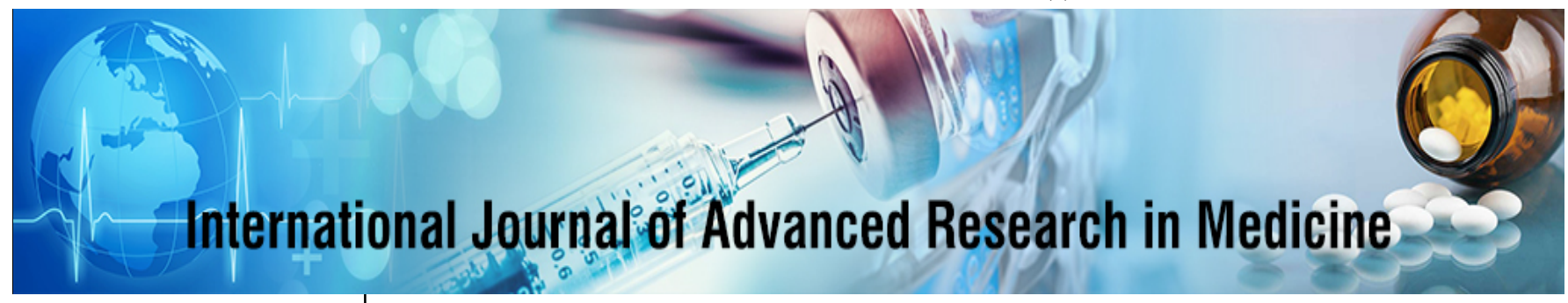

E-ISSN: 2706-9575

P-ISSN: 2706-9567

IJARM 2021; 3(2): 289-291

Received: 02-05-2021

Accepted: 22-05-2021

Dr. Guruprasad KG

Associate Professor, Department of Psychiatry, Index Medical College, Hospital and Research Centre, Index City, Indore, Madhya Pradesh, India
Corresponding Author: Dr. Guruprasad KG Associate Professor, Department of Psychiatry, Index Medical College, Hospital and Research Centre, Index City, Indore, Madhya Pradesh, India

\section{A study of student's and faculty's perceptions of online learning during the pandemic}

\section{Dr. Guruprasad KG}

DOI: $\underline{\text { https://doi.org/10.22271/27069567.2021.v3.i1e.271 }}$

\begin{abstract}
Background: During COVID-19, education has been shifted into the techno-economic culture. The shift should associate with plans to reduce this shift's impact on the normal learning process. The change to online in higher education entails reshaping our view regarding higher education, including institutions and students' needs. For instance, theoretical courses can be taught online. In contrast, the practical courses should be conducted face to face to ensure best teaching practices in monitoring and guiding students. So we were not sure of the perception of the faculty and students so this study puts in an effort to find the student's and faculty's perceptions of online learning during the pandemic. This is a very important study because as we know this Medical course is very much practically oriented.

Aims and Objectives: To study the student's and faculty's perceptions of online learning during the pandemic.

Materials and Methods: This study was done in Index Medical College, hospital and Research Centre, Index City, Indore, Madhya Pradesh. The study was done in two phases. The study was done from Feb 2021 to April 2021. A set of validated questionnaire was given to the students and teachers. 150 students MBBS phase 3 students were requested to participate in this study after taking written consent. All staff who were involved in the teaching of these students $(n=30)$ were also asked to fill in a questionnaire to understand their perceptions.

Results: There is a significant difference between the teachers and the student's perception scores.

Conclusion: The results of the present study show that online teaching can effectively supplement regular offline teaching.
\end{abstract}

Keywords: Covid-19, pandemic, faculty, students, perception

\section{Introduction}

E-learning which refers to the Electronic learning is the use of technology or an electronic media is used as a platform to give the students the content, make them understand the subject and also helps in their assessment ${ }^{[1]}$. E-Learning has a lot of potential in its easiness to use, the vastness of understanding and the information can be sought after the student's convenient time ${ }^{[2]}$. But as discussed earlier the conventional lectures are so much buried in the system that it is very difficult to be uprooted. But things have changed in the recent past. With the introduction of the competency-based medical education, these medical students are expected to hit the ground running ${ }^{[3]}$. E-learning is the ability to understand, interpret and apply this knowledge that is gained from a digital technology ${ }^{[4]}$. This epidemic has created a very good platform for medical students as well as the faculties to bring in a change. The success of the programme depends on a lot of factors. These can be students centric as well as the faculty centric ${ }^{[5,6]}$. For a long time, the faculties were unable to cope up with the pressure for this change. They were even reluctant ${ }^{[7,8]}$. But this time with this pandemic there was no alternative. There were very few efforts which were put to understand the difficulties and the solutions to implement e-learning ${ }^{[9,10]}$. So this study was one such sincere effort to find the perspectives of the students and the teachers in bringing a change [11].

\section{Aims and Objectives}

To study the student's and faculty's perceptions of online learning during the pandemic.

Materials and Methods

This study was done in Index Medical College, hospital and Research Centre, Index City, Indore, Madhya Pradesh. 
The study was done in two phases. The study was done from Feb 2021 to April 2021. A set of validated questionnaire was given to the students and teachers. 150 students MBBS phase 3 students were requested to participate in this study after taking written consent.

All staff who were involved in the teaching of these students $(n=30)$ were also asked to fill in a questionnaire to understand their perceptions.

\section{Exclusion criteria}

Students who did not consent.

Statistical analysis: student's t teat.

\section{Results}

Table 1: Students and teachers perception scores

\begin{tabular}{|c|c|c|c|c|c|c|c|}
\hline & Group & $\mathbf{N}$ & Mean & Std. Deviation & t & df & P value \\
\hline \multirow{2}{*}{ Perception } & Teacher & 50 & 38.12 & 7.34 & \multirow{2}{*}{-9.58} & 60.29 & $<0.001$ \\
\cline { 2 - 8 } & Student & 50 & 48.38 & 2.49 & & & \\
\hline
\end{tabular}

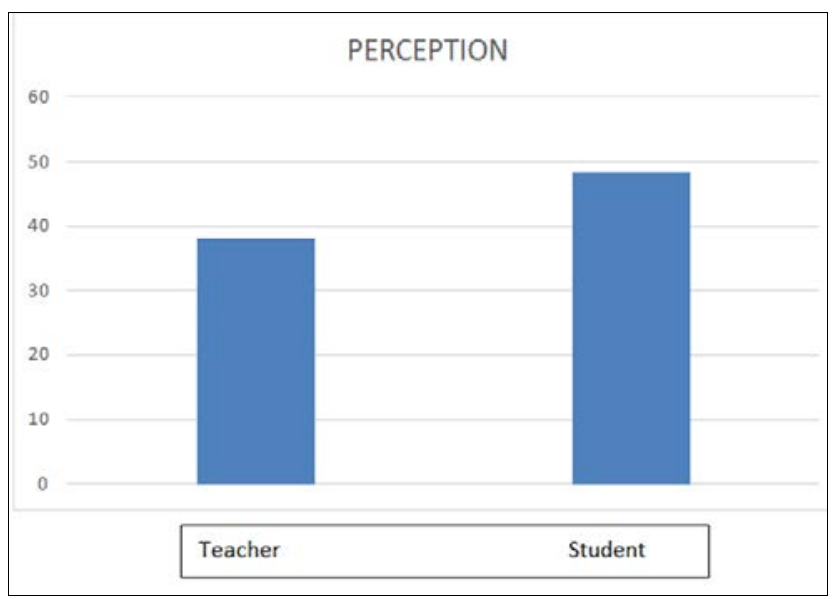

Graph 1: There is a significant difference between the teachers and the student's perception scores. The teachers were finding it difficult to teach. But the students actually were satisfied with this method. This may be due to the generation gap.

\section{Discussion}

During COVID-19, education has been shifted into the techno-economic culture. The shift should associate with plans to reduce this shift's impact on the normal learning process. The change to online in higher education entails reshaping our view regarding higher education, including institutions and students' needs. For instance, theoretical courses can be taught online. In contrast, the practical courses should be conducted face to face to ensure best teaching practices in monitoring and guiding students. Therefore, technology can make larger classes flexible and suiting students' needs.

Research on faculty members' perceptions and attitudes toward online learning emphasized the role of instructors in facilitating communication and earning with students. Instructors acknowledged the content expertise and instructional design as the factors in the success of online learning. Similarly, the call for staff and student training is mandatory for online learning success. The mode of education has turned into student-centered education, where students became independent learners. This is considered as an advantage as face-to-face instruction was teachercentered education, where students receive their education from their instructors. Online learning initiated students' role in using additional resources to discover their abilities as independent learners. The comparison between students' attitudes toward teaching the same interactive courses in online and face to face is similar. It is found that students performed equally at the same interactive courses in online and face-to-face instruction. Face-to-face instruction's success depends on regular class attendance, while the interactive classes relied on completing interactive worksheets. Therefore, online and face-to-face success is based on curriculum structure, mode of delivery, and completion rate. The COVID-19 outbreak shifts face-to-face education to online during the lockdown. This shift helps faculty integrate advanced technological skills in their teaching, which benefit students.

Online learning has been considered a useful tool for learning, cost-effectiveness, flexibility, and the possibility of providing world-class education. Online learning works as a tool to overcome abrupt crises. Online learning is considered as an entertaining way to learn. It has a positive impact on both students and teachers alike. Both faculty and students have optimistic opinions about online classes. Moreover, there is a positive correlation between students and faculty in their perception of teaching and learning.

\section{Conclusion}

The results of the present study show that online teaching can effectively supplement regular offline teaching post lockdown in one or other way.

\section{References}

1. Howlett D, Vincent T, Gainsborough N, Fairclough J, Taylor N, Vincent R. Integration of a case-based online module into an undergraduate curriculum: what is involved and what is effective? E-Learning 2009;6(4):372-84.

2. Mooney G, Bligh J. Information technology in medical education: current and future applications. Postgrad Med J 1997;73(865):701-4.

3. Costello E, Corcoran M, Barnett J, Birkmeier M, Cohn $\mathrm{R}$, Ekmekci $\mathrm{O}$ et al. Information and communication technology to facilitate learning for students in the health professions: current uses, gaps and future directions. Online Learn 2014;18(4):1-18.

4. Digital and Media Literacy for Today's Learners [Internet]. US Digital Literacy 2015 [cited 8 Aug 2020]. Available from: http:// digitalliteracy.us. Bedding G, Stoll B, Geissbuhler A, Klohn A, Stuckelberger A, Nko'o $\mathrm{S}$ et al. Computer literacy and e-learning perception in Cameroon: the case of Yaounde Faculty of Medicine and Biomedical Sciences. BMC Med Edu 2013;13(57):1-8.

5. Greenhalgh T. Computer-assisted learning in undergraduate medical education. BMJ (Clin Res Ed) 2001;322(7277):40-4.

6. Ozuah P. Undergraduate medical education: thoughts on future challenges. BMC Med Edu 2002;2(8):1-3.

7. Muilenburg L, Berge Z. Student barriers to online learning: a factor analytic study. Dist Edu 2005;26(1):29-48.

8. Gormley G, Collins K, Boohan M, Bichle I, Stevenson M. Is there a place for e-learning in clinical skills? A survey of undergraduate students' experiences and attitudes. Med Teach 2006;31(1):e6-e12. 
9. Cook D, Dupras D. A practical guide to developing effective web-based leaning. $\mathrm{J}$ Gen Intern Med 2004;19(6):698-707.

10. Albarrak A. Education in a technological world: communicating current and emerging research and technological efforts [Internet]. 1st ed. Formatex Research Center 2011.

11. Shachar M, Neumann Y. Differences between traditional and distance education academic performances: a meta-analytic approach. Int Rev Res Open Distributed Learning 2003, 4(2). 